\title{
Tribological Behavior of Functional Surface: Models and Methods
}

\author{
Pawel Pawlus * and Andrzej Dzierwa (D)
}

Citation: Pawlus, P.; Dzierwa, A. Tribological Behavior of Functional Surface: Models and Methods. Coatings 2021, 11, 333. https:// doi.org/10.3390/coatings11030333

Received: 9 March 2021

Accepted: 10 March 2021

Published: 15 March 2021

Publisher's Note: MDPI stays neutral with regard to jurisdictional claims in published maps and institutional affiliations.

Copyright: (c) 2021 by the authors. Licensee MDPI, Basel, Switzerland. This article is an open access article distributed under the terms and conditions of the Creative Commons Attribution (CC BY) license (https:/ / creativecommons.org/licenses/by/ $4.0 /)$.
Faculty of Mechanical Engineering and Aeronautics, Rzeszow University of Technology, Powstancow Warszawy 8 Street, 35-959 Rzeszow, Poland; adzierwa@prz.edu.pl

* Correspondence: ppawlus@prz.edu.pl; Tel.: +48-17-865-1183

Surfaces of solid bodies contain characteristic features, affecting the functional properties of machine elements. Surface topography restricts the contact area to a very small ratio of the nominal area [1]. It is a link between manufacturing and function. In some cases, the effect of surface topography on functional properties can be large. The effect of surface topography on contact (stiffness, conductivity, adhesive properties) is very high, followed by friction, lubrication, wear and fatigue. Loss due to wear and corrosion generates high costs. They can be reduced by surface engineering. The proper creation of surface topography may cause a decrease in friction and wear [2,3]. The frictional properties of machined elements can be improved by surface texturing [4-6]. Coatings make the surface life robust from wear [3,5-11] and corrosion [7-9]. The resistance to motion can be improved by change of the oil [12].

The aim of this Special Issue was to collect high-quality research papers, short communications, and review articles that focus on the tribological behavior of functional surfaces.

In [1], the methodology of prediction of the statistics of contact pressure from roughness analysis was proposed. It was applied to modeled fractal surfaces but could be also used to measure textures.

The effect of the disc surface topography after vapor blasting on tribological properties of a disc-ball assembly under dry friction conditions was studied experimentally [2]. This effect was shown to be substantial. Especially the shape of the ordinate distribution affected volumetric wear.

The Ti-6Al-4V alloy is widely applied for orthopedic implants. Its tribological properties can be improved by various engineering techniques, with PEO (plasma electrolytic oxidation) being one of them. The authors of [3] studied the effect of process parameters and surface finishing of the PEO-treated Ti-6Al-4V alloy using different process parameters on dry sliding behavior. Surface finishing by abrasive blasting with spheroidal glass beads led to a reduction in surface roughness height and to higher wear resistance and less friction.

The aim of [4] was to find the effect of the groove bottom profiles on the reduction of the friction force in lubricated sliding. Surface texturing led to a reduction in the friction force up to $55 \%$ compared to the untextured sample.

Surface texturing can be combined with coating. The authors of [5] found that the laser-textured surface combined with carbon coating (textured + coating) led to low wear and friction under lubricated conditions, in comparison to untextured, textured, and carbon-coated surfaces.

The authors of [6] studied experimentally and numerically the effects of DLC coating and surface texturing on friction reduction in the TEHL cam/tappet-contact. It was found that DLC coating led to a reduction in the solid and fluid friction force in a wide range of lubrication regimes. Texturing could reduce solid friction, increasing the fraction of fluid friction.

Epoxy-PTFE composite coatings are characterized by good functional properties such as a low friction coefficient and anticorrosion ability. However, due to small hardness 
they have a low wear resistance. The tribological properties and corrosion resistance of epoxy-PTFE composite coating were improved by nanoparticle modification [7].

There is a risk of tribocorrosion for sliding pairs operating in a seawater environment. In order to overcome this problem, elements with high hardness can be used. It was found that the $\mathrm{Cr} / \mathrm{CrN}$ PVD coating on AISI 1045 steel led to better tribocorrosion resistance than the gas nitrided with subsequent oxidation and impregnation coating [8].

Fe-based amorphous coatings obtained by supersonic plasma spraying and laser cladding exhibit excellent functional properties due to high hardness as well as high wear and corrosion resistance. The tribological and anti-corrosion behavior of these coatings on 45 steels were compared. Fe-based amorphous coating prepared by laser cladding led to better properties than plasma-sprayed coatings [9].

Manufacturers of turbomachines try to improve the engine performance. This can be achieved through the reduction of clearances between the rotor and the stator. However, due to it, a contact between these elements is possible. To reduce the severity of this contact, an abradable coating can be deposited along the stator circumference. The analysis of rotor/stator interactions considering the rotor angular speed and the initial clearances was performed in [10].

Among the coating methods, detonation spraying has a merit over other spraying methods due to lower operating temperatures and the high speed of particle flight. It was found that the properties of detonation coatings depended on the technological parameters of the spraying process. The best detonation coatings were characterized by small wear and high adhesive strength [11].

Ionic liquids can be used as new base oils or additives. Especially, cyano-based ionic liquids led to low friction. In [12], the lubricating properties of cyano-based ionic liquids against a tetrahedral amorphous carbon film were studied in reciprocating conditions. They were affected by the anion structure and ambient temperature. Low friction was achieved at $170{ }^{\circ} \mathrm{C}$.

The guest editors of this Special Issue would like to thank the authors for their valuable high-quality work submitted, the reviewers for their efforts and time spent in order to improve the submissions, and the publisher for their excellent work and cooperation. The contact between rough surfaces was also taken into consideration.

Author Contributions: Conceptualization, P.P. and A.D.; methodology, P.P. and A.D.; formal analysis, P.P. and A.D.; writing — original draft preparation, P.P.; writing-review and editing, P.P. and A.D.; All authors have read and agreed to the published version of the manuscript.

Funding: This research received no external funding.

Institutional Review Board Statement: Not applicable.

Informed Consent Statement: Not applicable.

Data Availability Statement: The data are available from the corresponding author upon request.

Conflicts of Interest: The authors declare no conflict of interest.

\section{References}

1. Bigerelle, M.; Plouraboue, F.; Robache, F.; Jourani, A.; Fabre, A. Mechanical Integrity of 3D Rough Surfaces during Contact. Coatings 2020, 10, 15. [CrossRef]

2. Dzierwa, A.; Pawlus, P.; Zelasko, W. The Influence of Disc Surface Topography after Vapor Blasting on Wear of Sliding Pairs under Dry Sliding Conditions. Coatings 2020, 10, 102. [CrossRef]

3. Bertuccioli, C.; Garzoni, A.; Martini, C.; Morri, A.; Rondelli, G. Plasma Electrolytic Oxidation (PEO) Layers from Silicate/Phosphate Baths on Ti-6Al-4V for Biomedical Components: Influence of Deposition Conditions and Surface Finishing on Dry Sliding Behaviour. Coatings 2019, 9, 614. [CrossRef]

4. Wos, S.; Koszela, W.; Dzierwa, A.; Pawlus, P. Friction Reduction in Unidirectional Lubricated Sliding Due to Disc Surface Texturing. Coatings 2020, 10, 221. [CrossRef]

5. Zhang, Y.; Fu, H.; Wang, X.; Liang, H.; Puoza, J.C.; Ji, J.; Hua, X.; Xu, X.; Fu, Y. Additional Tribological Effect of Laser Surface Texturing and Diamond-Like Carbon Coating for Medium Carbon Steel at Near Room Temperature. Coatings 2020, $10,929$. [CrossRef] 
6. Marian, M.; Weikert, T.; Tremmel, S. On Friction Reduction by Surface Modifications in the TEHL Cam/Tappet-ContactExperimental and Numerical Studies. Coatings 2019, 9, 843. [CrossRef]

7. Ying, L.; Wu, Y.; Nie, C.; Wu, C.; Wang, G. Improvement of the Tribological Properties and Corrosion Resistance of Epoxy-PTFE Composite Coating by Nanoparticle Modification. Coatings 2021, 11, 10. [CrossRef]

8. Kowalski, M.; Stachowiak, A. Tribocorrosion Performance of Cr/CrN Hybrid Layer as a Coating for Machine Components Used in a Chloride Ions Environment. Coatings 2021, 11, 242. [CrossRef]

9. Li, G.; Gan, Y.; Liu, C.; Shi, Y.; Zhao, Y.; Kou, S. Corrosion and Wear Resistance of Fe-Based Amorphous Coatings. Coatings 2020, 10, 73. [CrossRef]

10. Nyssen, F.; Batailly, A. Sensitivity Analysis of Rotor/Stator Interactions Accounting for Wear and Thermal Effects within Lowand High-Pressure Compressor Stages. Coatings 2020, 10, 74. [CrossRef]

11. Rakhadilov, B.; Buitkenov, D.; Sagdoldina, Z.; Seitov, B.; Kurbanbekov, S.; Adilkanova, M. Structural Features and Tribological Properties of Detonation Gun Sprayed Ti-Si-C Coating. Coatings 2021, 11, 141. [CrossRef]

12. Kawada, S.; Okubo, H.; Watanabe, S.; Tadokoro, C.; Tsuboi, R.; Sasaki, S.; Miyatake, M. Lubricating Properties of Cyano-Based Ionic Liquids against Tetrahedral Amorphous Carbon Film. Coatings 2020, 10, 153. [CrossRef] 